\title{
BMJ Open Perceived barriers to maternal and newborn health services delivery: a qualitative study of health workers and community members in low and middle-income settings
}

Joshua Sumankuuro, ${ }^{1,2}$ Judith Crockett, ${ }^{1}$ Shaoyu Wang ${ }^{1}$

To cite: Sumankuuro J, Crockett J, Wang S. Perceived barriers to maternal and newborn health services delivery: a qualitative study of health workers and community members in low and middleincome settings. BMJ Open 2018;8:e021223. doi:10.1136/ bmjopen-2017-021223

- Prepublication history for this paper is available online. To view these files, please visit the journal online (http://dx.doi org/10.1136/bmjopen-2017021223).

Received 18 December 2017 Revised 6 August 2018

Accepted 13 September 2018
Check for updates

(c) Author(s) (or their employer(s)) 2018. Re-use permitted under CC BY-NC. No commercial re-use. See rights and permissions. Published by BMJ.

${ }^{1}$ Youth Alive Ghana, Tamale, Ghana

${ }^{2}$ School of Community Health,Faculty of Science, Charles SturtUniversity, Orange, New SouthWales, Australia

Correspondence to Joshua Sumankuuro; ijoshua200@gmail.com

\section{ABSTRACT}

Objectives In considering explanations for poor maternal and newborn health outcomes, many investigations have focused on the decision-making patterns and actions of expectant mothers and families, as opposed to exploring the 'supply side' (health service provider) barriers. Thus, we examined the health system factors impacting on access to and delivery of quality maternal and newborn healthcare in rural settings.

Design A semistructured qualitative study using face-toface in-depth interviews with health professionals, and focus group sessions with community members, in eight project sites in two districts of Upper West Region, Ghana, was employed. Participants were purposively selected to generate relevant data to help address the study objective. The survey was guided by WHO standard procedures and Ghana Health Ministry's operational work plan for maternal and newborn care.

Setting Nadowli-Kaleo and Daffiama-Bussie-Issa districts in Upper West Region, Ghana.

Participants Two hundred and fifty-three participants were engaged in the study through convenient and purposive sampling: healthcare professionals (pharmacist, medical doctor, two district directors of health services, midwives, community health and enrolled nurses) $(n=13)$ and community members comprising opinion leaders, youth leaders and adult non-pregnant women $(n=240$ in 24 units of focus groups).

Results Results show significant barriers affecting the quality and appropriateness of maternal and neonatal health services in the rural communities and the Nadowli District Hospital. The obstacles were inadequate medical equipment and essential medicines, infrastructural challenges, shortage of skilled staff, high informal costs of essential medicines and general limited capacities to provide care.

Conclusion Implementation of the birth preparedness and complication readiness strategy is in its infancy at the health facility level in the study areas. Increasing the resources at the health provider level is essential to achieving international targets for maternal and neonatal health outcomes and for bridging inequities in access to essential maternal and newborn healthcare.
Strengths and limitations of this study

- The study provides the first comprehensive assessment of maternal and neonatal health delivery from the perspectives of community residents and healthcare providers in the two districts.

- The findings focus exclusively on views of participants' from sub-district health facilities, the district hospital, health service management and the community.

- The study aims to identify factors affecting maternal and newborn health outcomes, and thus the capacities of health facilities to provide quality health services was a component of the multisite study into community perspectives on birth preparedness and complication readiness interventions in the rural communities. This may not have rigorously incorporated all the issues required for a stand-alone evaluation of the health system.

- The results represent the views of health facility managerial and another frontline healthcare professionals, which may not reflect the views of all staff in the two districts.

- Much of this component of the study is qualitative, which has both strengths and limitations regarding processing and interpretation; hence, it lacks statistical rigour.

\section{INTRODUCTION}

Increasingly there are renewed commitments towards achieving the Sustainable Development Goals (SDGs) in advanced countries; however, in low-income and middle-income economies, inadequate services delivery initiatives persist. ${ }^{1}$ Globally, about $85 \%$ of obstetric complications occurred during pregnancy, labour and childbirth and the early postnatal period in 2015. ${ }^{2-4}$ Approximately 800 girls and women died as a result of pregnancy and childbirth-related complications in 2015 in sub-Saharan Africa $(\mathrm{SSA}) .{ }^{45} \mathrm{An}$ estimated $99 \%$ of all maternal deaths occur in 
developing countries and more than half occur in SSA. ${ }^{1}$ Although advanced countries recorded an estimated 11-14 deaths per 100000 in 2015, 511-652 deaths per 100000 were recorded in SSA within the same period. Ghana's maternal mortality rate was estimated to be between 358 and 319 per 100000 in 2015. ${ }^{56}$

WHO noted that $75 \%$ of maternal deaths occur due to avoidable causes including severe bleeding, sepsis, pre-eclampsia, unsafe abortion and complications in childbirth. ${ }^{1}$ Sixty-five per cent of women die in Ghana due to similar causes. ${ }^{1}$ The United Nations Population Fund (UNFPA) found that maternal deaths in Ghana could be reduced by $90 \%$ if expectant mothers were given ready access to emergency healthcare. ${ }^{7}$

In 2015, the SDGs negotiated new targets of reducing the maternal deaths ratio to less than 70 per 100000 live births, as well as ending preventable deaths of newborns by $2030 .{ }^{15}$ There are two maternal healthcare strategies proposed in the renewed commitments to stakeholders, with a high potential for preventing avoidable obstetric deaths: skilled attendance at birth and emergency obstetric healthcare. ${ }^{8}$ These measures are promoted through effective antenatal education and efficient management of referrals, coupled with adequate skilled healthcare professional attendance to both normal childbirths and those with obstetric complications. ${ }^{10} 11$ In many countries, these interventions form part of the birth preparedness and complication readiness (BPCR) strategy, a component of the antenatal care (ANC) programme. ${ }^{412} 13$

Although factors such as social, economic and cultural issues impact on the use of ANC and implementation of BPCR, ${ }^{14-16}$ there are also 'supply side' (healthcare provider factors) barriers to improving maternal health outcomes. These include commodities/logistics (drugs and non-drug consumables and medical equipment), skilled human resources, appropriate technology and the capacity to handle maternity cases. ${ }^{17}$ Availability of accessible emergency obstetric services (such as parenteral oxytocics, antibiotics and anticonvulsants, assisted deliveries, manual extraction of the placenta, blood transfusions and so on) are mandatory for the continuum of quality maternity healthcare. ${ }^{318}$ Preference for facility-based childbirth can be high when there is the appropriate quality of care, with the necessary medical facilities, such as equipment for surgery and blood transfusion services. ${ }^{19} 20$

For childbirth to be called skilled birth, the attendant must receive training from an accredited health institution and be licenced to practice. ${ }^{20}{ }^{21}$ The inadequacy of trained healthcare workers, including midwives, was identified as a significant barrier to improved maternal and neonatal health $(\mathrm{MNH})$ outcomes. Although public and private sector efforts have recently increased the numbers of skilled birth attendants (SBAs) on the global front, the opposite exists in some SSA countries. There, the nurse/ midwife to population ratio was estimated by the World Bank (for the periods of 2008-2014) as 0.9 per 1000 for Ghana $^{22}$ and less than 1 to over 95000 people in the study area since $2010,{ }^{23}$ compared with the global standard of 4.45 per 1000 people. $^{24}$

Ghana began an innovative decentralised health programme in 2004 aimed at addressing problems related to utilisation of SBAs by upgrading the skills of community health nurses (CHNs) to community health officers (CHOs) with basic midwifery skills. The essence of this initiative was to equip CHNs with the core competencies for managing labours and deliveries during emergencies. ${ }^{2526}$ The policy coincided with a ban on the utilisation of traditional birth attendants (TBAs) and was further challenged by an ongoing shortage of physicians. For example, in 2012, the Upper West Region (UWR) had 11 times fewer doctors compared with the Greater Accra (Ghana's capital) and Ashanti regions; well over 50\% of all doctors lived in Greater Accra with 20\% in the Ashanti Region. The remaining 30\% resided in the other eight health/geographic regions. ${ }^{23}$

Despite the implementation of the decentralised initiative, access to health facilities for delivery is still comparatively low, with approximately $44 \%$ of women in UWR giving birth in a healthcare facility. ${ }^{5}{ }^{25}$ The rate is the second lowest in Ghana and compares with $83 \%$ in the Greater Accra Region and $68 \%$ in the country overall. ${ }^{23}$ Many women in the rural communities continue to prefer care from TBAs. ${ }^{5}$ In many cases, women choose other alternatives due to demand-side barriers, such as lack of autonomy in decision making and financial and physical barriers to services, which discourages the utilisation of appropriate healthcare. ${ }^{5}$

There are also many supply-side barriers, despite local community potentials in rural communities such as those of the UWR of Ghana. These include direct bottlenecks in the health service delivery system impacting on potential service users, such as physical infrastructure, drugs, equipment, finances, human resources ${ }^{9} 17$ and appropriate transfer arrangements. ${ }^{14}$ The UWR has 174 health facilities with five district hospitals in the 10 districts and 1 municipality. However, the region has the smallest number of kilometres of tarred roads compared with the other nine regions of Ghana, with only Nadowli and Jirapa townships having a direct link to the regional hospital via tarred road. ${ }^{23}$ Before the study, an ex-post evaluation of Country Programme Five (CP5) for Ghana by the UNFPA found $36(90 \%)$ poor performing districts out of 40 districts in 5 regions (8 districts in each) with regard to $\mathrm{MNH}$ indicators. ${ }^{27}$ Three (about $8.3 \%$ ) of these underperforming districts were in UWR (Nadowli, Sissala East and Wa West). CP5 (2006-2010) focused on three areas: (A) reproductive health, population and development; (B) gender equity and women's empowerment; and $(\mathrm{C})$ reproductive health and HIV/AIDS. ${ }^{27}$ As a result of these limitations, UNFPA implemented Country Programme Six (CP6) (2012-2016) in those locations, which included the two study districts: Nadowli/Kaleo and Daffiama/Bussie/Issa. Although the package included key logistics and equipment, as well as skills upgrade of staff, there has not been any known investigation into the 


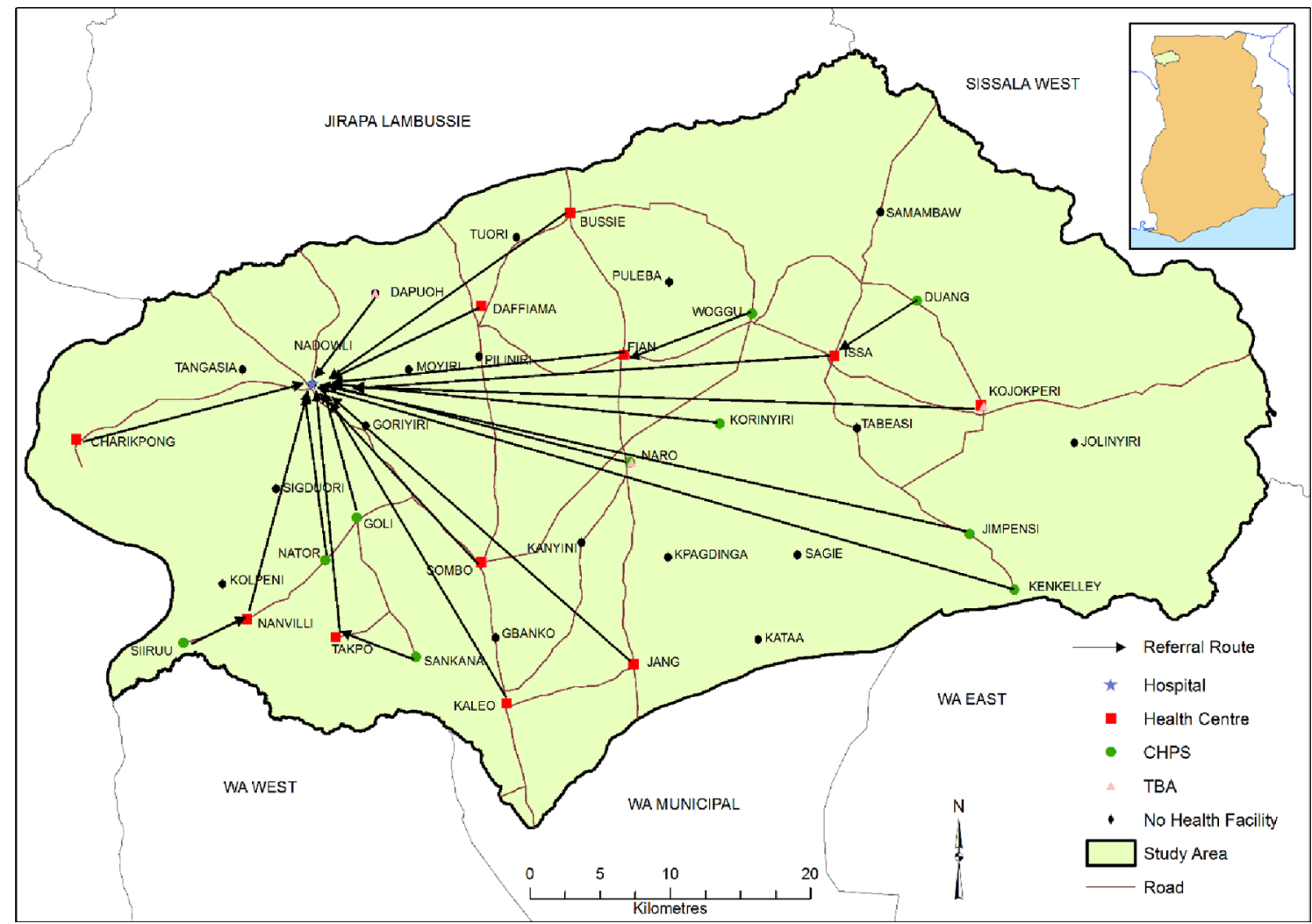

Figure 1 Study communities and health facilities.

current state of maternal healthcare delivery services in these regions. ${ }^{19} 2528$ Therefore, this study answered the question: "what are the perceived barriers to maternal and and newborn service delivery in Nadowli-Kaleo and Daffiama-Bussie-Issa Districts of Ghana'. Key indicators covered were: staff capacities, basic equipment, service space/bed capacities, water and lighting facilities, medicines and other essential supplies for service delivery as well as staff/maternal relations.

\section{METHODS \\ Study setting}

The study was a semistructured qualitative design using face-to-face interviews to explore barriers to skilled service delivery and utilisation in eight purposively selected study sites in the UWR of Ghana: four in Nadowli/Kaleo and four in Daffiama/Bussie/Issa. The study area had a two-tier health system: the district level (the hospital) and 29 subdistrict level health facilities (13 health centres (HCs) and 16 Community-Based Health Planning and Services (CHPS) compounds that are the lowest order in the Ghana Health Service structure) ${ }^{29} 30$ (figure 1). The CHPS compounds provide preventive services and obstetric first aid including immunisations, vaccinations, health promotion and health education activities, while the HCs provide both preventive and curative services to the communities. Six of these communities did not have access roads to the nearest hospital (Nadowli Hospital).
The population of Nadowli/Kaleo district was 61561 ( $46.7 \%$ males and $53.3 \%$ females), constituting $8.8 \%$ of the region's population. ${ }^{30}$ Daffiama/Bussie/Issa Districts had a population of 32827 (48.7\% males and $51.3 \%$ females) representing $4.7 \%$ of the people of UWR. ${ }^{29}$

\section{Conceptual framework}

Health facility outputs are measured by the number of interventions for normal and emergency healthcare provision. ${ }^{31-33}$ In order to achieve skilled maternal and newborn attendance, a prerequisite to reducing avoidable infections and other morbidities and mortalities, the Ghana Health Service, in accordance with WHO policies, instituted measures to improve access to skilled and quality care in the country. The quality of MNH service delivery is assessed using benchmarks: human resources, logistics, referral policy/processes and service delivery space/physical infrastrure. ${ }^{24} 3132$ The monitoring and evaluation frameworks for accessing health facility practices in relation to BPCR by Johns Hopkins Program for International Education in Gynaecology and Obstetrics (JHPIEGO $)^{31}$ was adapted to guide the design, interpretation and reporting of the findings. The policy document prioritise timely access to relevant and quality care, in compliance with referral procedures, management of emergency obstetric complications, infection control procedures and strict adherence to the appropriate protocols and professional standards (table 1) to improve maternal and newborn care quality in facilities. ${ }^{23} 3233$ 


\section{Table 1 Indicators for monitoring health facility practice of BPCR}

\section{Factors affecting BPCR of health facilities}

\section{Definition}

Skilled human resource base of health facilities

Availability of midwives, anaesthetists and specialist doctors.

Health facility infrastructure

Ready lighting system in facilities and spacious labour rooms.

$\begin{array}{ll}\begin{array}{l}\text { Logistics and equipment } \\ \text { availability }\end{array} & \begin{array}{l}\text { Health facilities equipped } \\ \text { with logistics and equipment } \\ \text { necessary for providing } \\ \text { quality and timely MNH care. }\end{array} \\ \text { Referral management } & \begin{array}{l}\text { Transport or ambulance } \\ \text { availability for efficient } \\ \text { and effective transfer of } \\ \text { emergency obstetric cases. }\end{array}\end{array}$

Source: adapted from existing literature and the BPCR toolkit by JHPIEGO. ${ }^{31}$

BPCR, birth preparedness and complication readiness; $\mathrm{MNH}$, maternal and neonatal health

\section{Study design}

Health services delivery and related factors influencing BPCR are complex, ${ }^{19202325}$ which necessitates the need to explore them from the perspectives of both community members and service providers. A qualitative approach was considered to be most appropriate, using focus group discussions (FGDs) and in-depth interviews (IDIs). The district health management provided time series data using a structured survey of their resource capacities and logistics, and referral management prospects and challenges.

\section{Participant selection}

Written informed consent was obtained from each participant. Participants were selected in the following ways:

\section{Focus group participants}

A combination of key informant and purposive sampling procedures was adopted to identify and select a convenient sample of opinion leaders $(n=80)$, youth leaders aged 18-35 years $(n=80)$ and nonpregnant women (who had childbirth experiences) $(n=80)$ to provide data in 24 different group discussions, three in each community. The community representative, who is a non-partisan but statutorily elected official representing each community at the district level, assisted in identifying potential participants for the FGDs. The sample sizes were predetermined to facilitate data saturation and potential transferability of the findings to other contexts and settings (see the link for the detailed questionnaire and interview guide for all participant groups https://doi.org/10.1371/journal. pone.0185537.s001).

\section{Healthcare staff}

Skilled healthcare staff were included in the study to provide their opinions on health services delivery and outcomes. On receiving written support from the health directorates, the staff in charge of each of the healthcare facilities in the study area were asked to participate in the study. Three 'other nurses' who were providing health services but not in managerial positions were purposively selected to submit further insights into expectant motherANC provider relationships and uptake of medical advice.

A summary of all participants can be found in table 2 .

\section{Research instruments}

An interview schedule containing structured and unstructured questions was applied to health professionals and surveyed staffing and logistical capacities to provide quality maternal health services, healthcare financing issues and preparedness for birth and complications.

A similar semistructured discussion guide was used for the FGDs with the community members, which enabled in-depth investigation into community perspectives of BPCR interventions, the causes of maternal and neonatal morbidities and mortalities, sociocultural beliefs and practices impacting the use of maternal and newborn health services and barriers to healthcare uptake. The semistructured interview guides were not pretested and were conducted in 'Dagaare' (the local language).

Table 2 Study participants, data types and sex disaggregation

\begin{tabular}{|c|c|c|c|c|c|}
\hline Participants & $\begin{array}{l}\text { Age range } \\
\text { (years) }\end{array}$ & Number & Data type & Sex disaggregation & No. of communities \\
\hline Opinion leaders & $18-59$ & 80 & Qualitative & $\begin{array}{l}22 \text { women, } \\
58 \text { men }\end{array}$ & 8 \\
\hline Non-pregnant women & $18-59$ & 80 & Qualitative & All women & 8 \\
\hline Youth & $18-35$ & 80 & Qualitative & $\begin{array}{l}40 \text { women; } \\
40 \text { men }\end{array}$ & 8 \\
\hline
\end{tabular}




\section{Data collection}

The FGDs were completed first, before the IDIs with the healthcare providers. This arrangement provided the opportunity to cross-examine relevant issues emerging from the discussions. Some of the key emergent issues identified included the sale of ANC routine drugs and other essential medicines to clients with active health insurance subscriptions and the challenges associated with the insurance scheme, as well as patronage of the services of TBAs.

Convenient venues were arranged within the communities for the FGDs. All discussions and surveys were in the local language (Dagaare), as illiteracy was high. ${ }^{29} 30$ The IDIs were conducted in English at scheduled locations in the health facilities. JS received training from the Charles Sturt University Research Office on survey design, data collection and analysis, supervised by JC and SW. Two experienced researchers (JS and FT) collected the data. All surveys, IDIs and FGDs, were completed as planned, thereby resulting in a higher than anticipated response rate. Data were collected within two periods: FebruaryJune 2016 and January-May 2017.

\section{Data processing}

All interviews and group sessions were tape-recorded with the informed consent of the participants. To achieve accuracy and dependability of the data, all audio recordings, except those of the health professionals, were first transcribed (hand written) in 'Dagaare' and then translated into English by JS. JS is a native of the region and writes and speaks the local dialect. The interviews with healthcare staff were transcribed in English. Two separate individuals from the Ghana Institute of Languages were engaged to verify the recordings with the transcripts. WHO's four-stage process for translation and adaptation of instruments guided the transcription process. ${ }^{34}$

\section{Data analysis}

Analysis of the qualitative data began in the field. After each interview, notes were made containing: (A) emerging opinions from the participants and how they could be noted and applied to other interviews, ${ }^{5}$ (B) what went well or not so well; (C) what should be done differently in future interviews and (D) physical observations of health facilities, surface nature of roads and interactions among participants and nurses. This interim analysis enabled the researcher to add follow-up questions to the interview schedule to clarify issues as they emerged.

NVivo (V.7.5) was used to analyse the qualitative data. Analytical text categories and themes related to 'logistics, equipment, staffing, essential medicines' emerged from the computerised coding using the NVivo, which were complementary themes to a priori topics and subthemes identified in the quantitative analysis and existing literature and experience. The different factors affecting service delivery and skilled healthcare utilisation emerged as significant themes from the data (interview/FGD transcripts, right notes, field observations/reflections). These were thoroughly read and re-read to identify index topics and categories. Participant opinions were subsequently chosen to support the themes. Finally, both the predetermined and emerged themes were pooled together to address the research question.

\section{Patient and public involvement}

The study design emerged from the implementation of the UNFPA CP6. Thus, the participants and the public were not directly involved in the conceptualisation and design of the study. Nevertheless, the findings of the study would contribute to policy and service delivery interventions in Ghana and similar geographical locations, which is the reason that the views of the intended beneficiaries were obtained for the study.

\section{RESULTS}

Four congruent themes under the conceptual framework determine the order of the results. The issues identified are categorised as (1) human resources, (2) facility infrastructure, (3) health logistics and equipment and 4) referral management (table 3 ).

\section{HUMAN RESOURCE CAPACITIES IN HEALTH FACILITIES Nadowli District Hospital}

At the time of the survey (2016), there were three resident medical doctors (one woman and two men) in the hospital (table 3). Ten midwives provided care in the maternity ward, conducting labours and deliveries as well as admissions and general gynaecological care. Non-midwives (community health and enrolled nurses (ENs)) did not attend to childbirths or provide any other support in managing labour at the maternity unit (because of the definition of skilled attendance) regardless of the number of midwives on duty. Two anaesthetics nurses were on duty in turns on weekdays for 8 hours daily (table 4). The number of professional staff has been unstable over the years (2013-2016) with the number of midwives decreasing (table 4 ).

\section{The effect of staff shortages on service delivery}

The professional staff shortages at Nadowli District Hospital were found to be contributing to staff role stress and unnecessary referrals of pregnancy and newborn cases to other hospitals (mostly to Wa regional or Jirapa district hospitals).

It is only two anaesthetists that are in the hospital. Sometimes, one will be on leave leaving only one. We could call the anaesthetist, and it [the phone] is switched off. Other times, he will tell us he is very far away. The doctors too are sometimes few, maybe the doctor is gone on official duty and very far away from the hospital or maybe throughout the day and night; the doctor might have worked so hard that if he tries to attend to the next case, the outcome may 


\begin{tabular}{|c|c|}
\hline Theme & Subthemes (factors) \\
\hline $\begin{array}{l}\text { Human resource capacities } \\
\text { in health facilities }\end{array}$ & $\begin{array}{l}\text { Nadowli District Hospital } \\
\text { Staff shortages on service } \\
\text { delivery. } \\
\text { Staffing and the effects on } \\
\text { subdistrict health facilities } \\
\text { Skilled attendance at birth. } \\
\text { Nurses-expectant mother } \\
\text { relationships. } \\
\text { Management of basic and } \\
\text { emergency obstetric cases. }\end{array}$ \\
\hline Health facility infrastructure & $\begin{array}{l}\text { Service space in maternity } \\
\text { units. } \\
\text { Water supply. } \\
\text { - Lighting system. }\end{array}$ \\
\hline $\begin{array}{l}\text { Medical equipment and } \\
\text { logistics availability and } \\
\text { functionality }\end{array}$ & $\begin{array}{l}\text { Nadowli District Hospital } \\
\text { Logistics shortages } \\
\text { on infection control } \\
\text { procedures. } \\
\text { Subdistrict health facilities } \\
\text { Essential medicines at the } \\
\text { subdistrict level. } \\
\text { Transport services. }\end{array}$ \\
\hline $\begin{array}{l}\text { Management of referrals of } \\
\text { emergency obstetric and } \\
\text { newborn complications }\end{array}$ & $\begin{array}{l}\text { Typical referral management } \\
\text { procedure at the subdistrict } \\
\text { healthcare level. } \\
\text { Transport services during } \\
\text { referrals. } \\
\text { National ambulance } \\
\text { services. } \\
\text { Public and private transport } \\
\text { services. } \\
\text { Managing information and } \\
\text { communication during } \\
\text { emergency obstetric } \\
\text { referral. }\end{array}$ \\
\hline
\end{tabular}

be severe. Therefore, it is referred out of the facility. (IDIs, other nurses)

Midwife shortages prolonged the time mothers spent accessing ANC services.

Due to a shortage of midwives, pregnant women can spend the full day seeking care [at the hospital], which discourages the very distant communities from seeking care. (IDIs, other nurses)

\section{Staffing and the effects on subdistrict health facilities}

Data from the eight subdistrict health facilities indicated shortages of skilled healthcare staff were a persistent challenge to healthcare management. Among the surveyed health facilities, $62.5 \%$ (five) (three HCs and two CHPS compounds) had resident midwives, while Nanvilli HC, Duang CHPS (DCHPS) and Jimpensi Community-Based Health Planning and Services (CHPS) compounds (JCHPS) had no midwife. Jang Health Centre had two midwives (but only one at

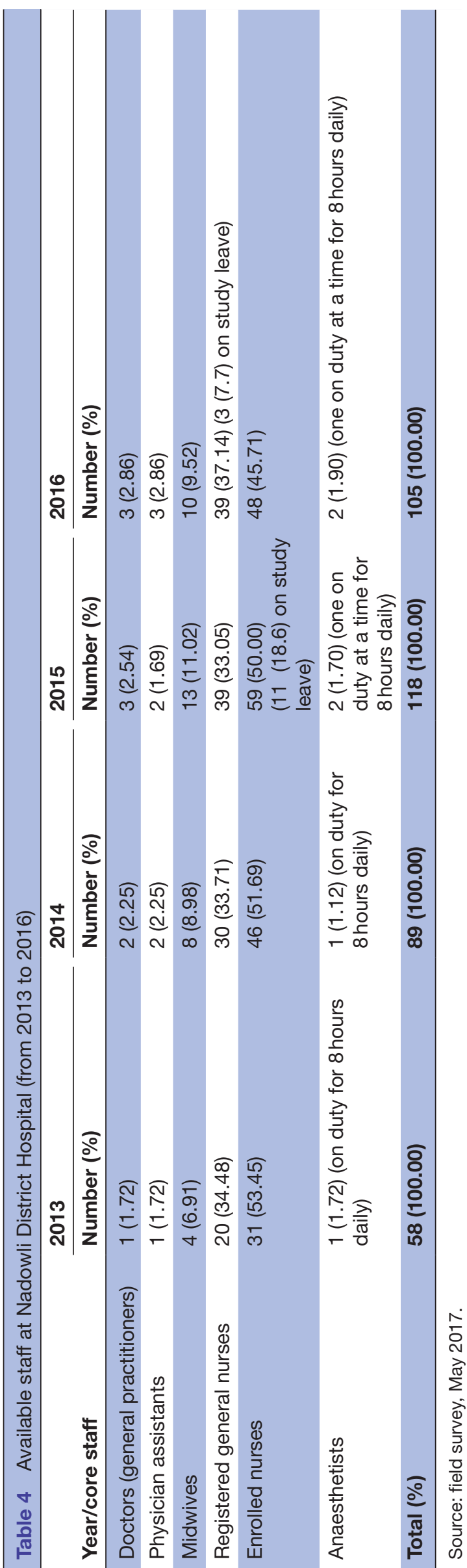


post). The midwife was assigned to each health facility to provide all MNH services to clients (ANC, labour and childbirth care) and to deal with other general ailments of the populace, in addition to performing administrative roles as facility head.

Almost all health facilities had CHNs (13 in total) and ENs (6 in total). There was also one registered general nurse, one physician assistant, two field technicians and one mental health professional located in the region.

\section{Skilled attendance at birth}

WHO's definition of 'skilled attendance' at birth denotes employing the services of a midwife or doctor, which is a significant challenge in rural Ghana. The staffing challenges motivate the health service management at the district level to endorse community health nurse and EN supervised delivery as skilled birth, even if they have had no midwifery training.

How about the CHNs we put at the CHPS compound and ask them, when a woman is delivering, they should catch (receive)? Therefore, I [DoN] think any delivery that is supervised by a trained health worker should be considered skilled delivery. So, the CHNs are forced to always refer to facilities with midwives, and considering the distances, we record poor outcomes or home births. Will they go? (IDIs, other nurses, DoN 1)

The number of midwives in the Daffiama/Bussie/Issa district was deemed inadequate to serve the numbers of pregnant women:

The district has five health centres and twelve CHPS compounds. However, we currently have seven (7) midwives at the post which is inadequate to provide maternal healthcare to many pregnancy issues we face each day. Even the district capital, Issa needs more than one midwife; but we are forced to make do with just one. (IDIs, other nurses, DoN 1)

The midwives themselves agreed with the above assessment:

I am the only midwife and always stressed up. Whenever I have two or three labour cases at the same time, it is stressful working all the time. Also, if I am conducting ANC and a labour case is brought in, I suspend the ANC and attend to that one. Sometimes, expectant mothers default ANC when it happens that way, and it becomes difficult tracing them because I am alone. (IDIs, midwife 3, CHPS)

The skills shortage affected the quality of prenatal and postnatal service delivery:

We do not have enough skilled staff. Therefore, the expectations of clients are sometimes not met. As I said earlier, one midwife is unable to explain certain issues clearly for pregnant women to understand because she has limited time to carry out all (the) education and detail[ed] explanations. (IDIs, other nurses)

\section{Nurses-expectant mother relationships}

Negative attitudes of some nurses towards pregnant women can act as a deterrent to expectant mothers:

Expectant mothers receive cheeky words from the nurses, so some do not receive maternal healthcare at the clinic because they have received enough of the insults. They are afraid to divulge the truth for fear of receiving worse treatments in subsequent attendance. (FGDs, non-pregnant women, Naro/Korinyiri)

Discussants in another community suffered similar treatments:

I have not been to other clinics, but the nurses in our clinic do not give us attention at all whenever we seek care at night or evening. They might not even utter a word, before going back into their residences. When the client or family insist, they write a referral letter. Given the odd hour, how are we going to manage the case to Wa or Nadowli hospital? (FGDs, non-pregnant women, Jang)

Although HCs and CHPS compounds are expected to provide a 24-hour service to communities, some clients were denied care.

Some nurses would even tell us they do not run shifts and so will not work after 2 pm. (FGDs, non-pregnant women, Jang)

\section{Management of basic and emergency obstetric cases}

Among the eight subdistrict health facilities (HCs and CHPS compounds), seven (85.5\%) regularly only received primary obstetric cases and one (12.5\%) received both basic and comprehensive emergency obstetric cases. However, half of the health facilities managed one comprehensive emergency obstetric case each in the 3 years (2013-2015) preceding the study and two HCs confirmed they had managed five or more obstetric complications in the same time frame. Three-quarters of the subdistrict healthcare settings did not have the necessary skilled staff to manage obstetric cases.

\section{HEALTH FACILITY INFRASTRUCTURE Service space in maternity units}

Nadowli District Hospital was the only public hospital serving the two districts and was the highest referral facility. It had 76 beds, including 12 beds for the maternity ward and 2 delivery beds in the labour section.

For the labour ward, we have only three beds, out of which only two are used. We use the third bed as a last resort, although it is not meant for childbirth. It is for examination. In critical situations, we are forced 
to conduct delivery in the manual vacuum aspiration (MVA) room. (IDIs, other nurses)

\section{Water supply}

None of the subdistrict health facilities had potable water for usage by the workers and cleaning of the premises, meaning that expectant and postnatal mothers were often found drawing water for the health facilities or were forced to return home to draw water for nurses if they sought care without it. Alternatively, the midwives would have to leave the mothers in the healthcare setting in search of water for cleaning. Thus, 'some expectant mothers get discouraged from giving birth there' (IDIs, other nurses, DoN 1).

\section{Lighting system}

Ghana government's rural electrification initiatives were understood to have covered a significant part of the countryside. Despite this, not all old or even recently constructed health facilities were connected to the national grid. For instance, Duang CHPS was inaugurated around 2015 but continues to experience intermittent power outages from a faulty wiring system. A similar limitation was found at Charikpong HC (one of the premier health facilities in the district) and Nanvilli HC depended on patients to provide fuel to power the facility's generator; without fuel, either the delivery would have to be transferred elsewhere or be carried out in the presence of often inappropriate family members:

We do not have a source of water and light. When I am conducting delivery, I use a lamp or generator. However, the generator must be fuelled by the relative of the expectant mother. Due to the cost, they are not able to afford. I use torchlight when there is a tear. I had a labour case where the mother sustains some lacerations which I have to suture. Sometimes, I involve the relatives because I cannot hold the torchlight while suturing, and patients' rights are violated, because that may not be the right person to see her nakedness. (IDIs, midwife, HC)

\section{MEDICAL EQUIPMENT AND LOGISTICS AVAILABILITY AND FUNCTIONALITY \\ Nadowli District Hospital}

The hospital had inadequate equipment despite the significant threshold population it serves. The entire hospital operated on one anaesthetic machine, a dysfunctional haematology analyser at the laboratory and an incomplete resuscitation table, all of which had the potential to affect service delivery. Despite the occurrence of stillbirths and neonatal deaths, there was no neonatal intensive care unit in the hospital. Other challenges included:

Frequent power fluctuations are causing significant breakdowns in the equipment, that is, blood bank refrigerators, autoclaves, air conditioners and theatre lamps. It further affects service delivery in the maternity section. (IDIs, other nurses)

Only a poorly supplied resuscitation table for preterm delivery care was available:

Resuscitation table requires many items so that in case a baby is born and is asphyxiated; we can conduct it with ease. The table we have now is not wellequipped. We are only managing to save lives. (IDIs, other nurses)

\section{Subdistrict health facilities}

All the HCs had midwives and conducted childbirths. While the CHPS compounds without midwives were not allowed to conduct childbirths or deal with other emergency obstetric situations, a bed and set of delivery equipment were provided for all compounds. Only two HCs had a manual vacuum aspiration kit. There were other necessary (and essential) equipment available for checking vital signs at the HCsblood pressure apparatus, thermometer, weighing scaleincluding foetoscope and foetal Doppler, but not all were in usable condition. Some CHPS compounds did not have necessary logistics such as a vaccine fridge:

There is electricity here now, but we do not have a vaccine fridge. When we even conduct childbirth, we have to ride to Kojokpere health centre for poliomyelitis vaccine for the newborn and return the remaining for storage. When expectant mothers are around the $20^{\text {th }}$ week of gestation, we administer tetanus toxoid injection (TTI), but the vaccine cannot be stored here. (IDIs, CHPS)

Similarly, the CHPS compounds often did not have the mandatory equipment to manage emergency deliveries or resuscitate asphyxiated newborns, such as Ambu bags, meaning that at times 'we see that the woman will be struggling and we cannot do anything to help' (IDIs, in-charge, CHPS).

\section{The effect of logistics shortages on infection control procedures}

Some health facilities did not have the necessary daily non-drug consumables for administering care. While Rapid Diagnostic Test kits (for malaria) were readily supplied to some facilities, infection control items such as facilities for handwashing and hand gloves were often not provided for some facilities:

We have had consignments on the RDT which had no gloves included. Therefore, we do use bare hands to conduct the tests. The improvised hand gloves you [interviewer] saw me wear, were old gloves I found because we do not have hand gloves in the entire facility and the current RDT kits were not supplied with gloves. (IDIs, in-charge, male, CHPS)

Another participant identified how a shortage of gloves was 'the reason I improvised with hazardous materials (rubber bag) to conduct HIV/AIDS and Syphilis tests' (IDIs, in-charge, male, CHPS). 
The National Malaria Control Programme scaled up access and universal coverage to provide long-lasting insecticide bed nets to all expectant mothers and children who under 5 years of age; however, some pregnant women in these districts were denied access to these services. Some health facilities were not included in the regular consignments of supplies.

When I came here, there were no mosquito nets in the facility. We do not also have sulphadoxine-pyrimethamine (SP); it is prophylaxis for malaria prevention in pregnancy. Since I came to the installation, there has not been any SP for the pregnant women. (IDIs, midwife 4, HC)

\section{Essential medicines at the subdistrict level}

While 'the WHO protocol recommends antibiotics for pregnant women who give birth newly' (IDIs, other nurses), the National Health Insurance Drug lists for CHPS compounds prohibit prescription of antibiotics to newly delivered mothers, despite it being mandatory. This is because the CHPS 'compound is a small facility. When we prescribe it, NHIS refuse to pay. Therefore, we sell it to them [the patient] which they always complain they do not have money to pay for medicines' (IDIs, other nurses).

Some health facilities did not have other essential medicinal products for conducting childbirth.

I came in December 2015, and there was no oxytocin, no Vitamin $\mathrm{K}_{1}$ for the newly born babies. As at now, still, there is no vitamin $\mathrm{K}_{1}$ in the facility. (IDIs, midwife $3, \mathrm{HC}$ )

As a result of other changes in health policy, there were other limitations placed on $\mathrm{HC}$ midwives prescribing certain essential medicines to manage labours.

At the health centre, we cannot use the Zeamatin (if the woman is having preterm, we cannot give, we have to refer to Nadowli Hospital). (IDIs, midwife 1, HC)

\section{Transport services}

The majority of the health facilities did not provide transport (eg, motorbikes) for midwives to visit communities, thereby restricting their ability to engage in health education, to follow-up on women not attending ANC and to carry out routine immunisations:

We have so many maternal and newborn programmes that require motorbikes, but we do not have enough motorbikes for all the facilities. Aside from the bikes, some of the communities are hard-to-reach. (IDIs, DoN 2)

\section{MANAGEMENT OF REFERRALS OF EMERGENCY OBSTETRIC AND NEWBORN COMPLICATIONS}

The referral hospital reported receiving emergency obstetric cases from the HCs and CHPS compounds.
Expectant mothers referred during labour were 54 (5.22\% of births) in 2012, 36 ( $10 \%$ of births) in 2013 , 24 (7.09\% of births) in 2014 and 17 (7.13\% of births) in 2015 .

\section{Typical referral management procedure at the subdistrict} healthcare level

The model below typifies the referral pattern that pertains to the communities, with a focus on worst case scenario (figure 2).

All four HCs received labouring mothers and obstetric referrals from the CHPS compounds and across all communities in their catchment area, with the number of referrals significantly influenced by their geographical location. Nearly all maternity cases brought to the HCs originated from the remotest communities.

\section{Transport services during referrals}

National ambulance service

There were two groups of ambulance services operating in both districts to improve health service delivery: the hospital ambulance service and the national ambulance service (NAS). Each of them had one vehicle serving the two districts and other districts within its catchment area. The NAS station was situated at Nadowli but served any other district that called them for emergencies within the UWR. Thus, the hospital vehicle and the NAS vehicle were both stationed at Nadowli leaving the far hinterland without ready access to vehicular transport during emergencies. There was one dysfunctional ambulance vehicle for all referrals to and from the Nadowli hospital. Daffiama health centre was the only health facility in Daffiama/Bussie/Issa district with double cabin pickup for emergency referrals of all patients as well as day-to-day operations of the facility. There were no available means of transport in any of the subdistricts except Daffiama health centre, with their car serving as an official vehicle as well as transferring emergency obstetric and newborn complications. However, the location of Daffiama health centre is within 20 min drive of Nadowli hospital, closer than all other communities in the district, which leaves the remainder of the district without any emergency vehicles.

\section{Public and private transport services}

Lack of ambulances means that the majority of clients are reliant on public means of transport. This implies the client and family will usually have to wait until certain hours in the day to access transport:

If we are to send someone to a referral facility and it is around $10 \mathrm{am}$, the client cannot get means because all the vehicles go to Wa [region's capital]. Unless in the evening that they return to the community. (IDIs, CHO, CHPS)

The search for affordable transport, whether it be by tricycle, motorbike or pick-up car, can often result in a delay in accessing the next level of care. 


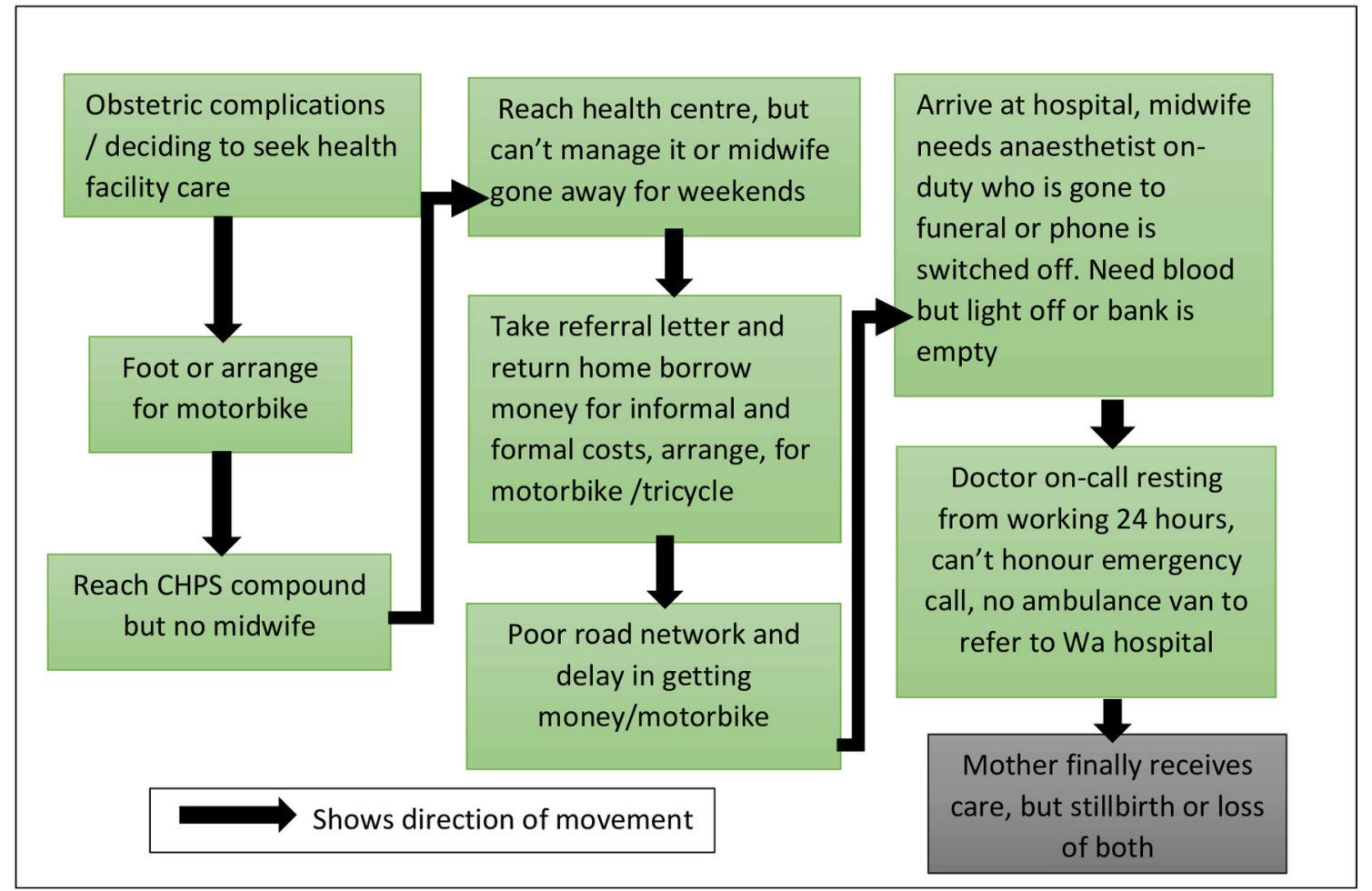

Figure 2 Pictorial view of typical referral management in the study area.

During referrals, we wait for several hours before they can get modes of transport to the next level of healthcare. We do not also have laboratory services in the entire district so for us to conduct the routine laboratory investigations, we refer expectant mothers to Nadowli or Wa which becomes a challenge for many pregnant women. Even for pregnant women to get money to arrange for means of transport to the next level of care is always a problem. (IDIs, midwife, CHPS)

As a general rule, it was the responsibility of the expectant mother (or her family) to arrange for means of transport during emergency referrals because of a shortage of emergency vehicles. The cost often limited the ability of the expectant mother to receive care.

\section{Managing information and communication during emergency obstetric referral \\ The telecommunication sector presents a significant challenge to managing referrals in some communities. Vodafone and MTN Ghana telecommunication service providers had network coverage in the communities, although some communities had challenges accessing networks. During the field data collection exercise, the first author found that Charikpong, Nanvilli/Siruu, Jimpensi/Kenkelley and Duang communities had inter- mittent telecom networks. Therefore, mobile phone users had the option to either climb up a tree in a stra- tegic area or hover around various signal hotspots (identi- fied by the community) to make a phone call. The facility heads agreed with this observation, noting that:}

Our mobile phones network is a serious challenge... Therefore, when we have an emergency case, how to link with the national ambulance or the ambulance at Nadowli hospital is always a problem. (IDIs, midwife 2, CHPS)

\section{DISCUSSION}

By using the structure of the BPCR monitoring and evaluation framework for health facilities, the results of this study provide an insight into the preparedness of healthcare facilities to provide efficient obstetric and newborn care to the communities.

As far as we know, this study is one of the first to assess health facility preparedness for birth complication readiness in the Nadowli-Kaleo and Daffiama-Bussie-Issa districts of Ghana. The barriers to improved maternal health service utilisation and the potential to address these complexities are well documented in the literature. Extrinsic and intrinsic inequities in access, including transport arrangements and management of referrals, are also identified to support existing findings in related districts of the UWR. ${ }^{14}$

The skills upgrading programme introduced by the Ghana Health Service for subdistrict level staff (since 2004) ${ }^{19} 35$ sought to increase skilled staffing capacities of the facilities. However, there were inadequate numbers of skilled healthcare staff (ie, licenced midwives and medical doctors) in the study areas, which provided many challenges for the few staff available, including role stress and 
undignifying behaviour patterns towards mothers. This supports previous observations. ${ }^{23}$ At the hospital, one midwife may be on duty to manage all new admissions and emergency referrals for the entire maternity unit. There were no remuneration packages to motivate the few skilled staff, aside from the average monthly salary. The impact of shortages was compounded when referrals were made between district hospitals because of lack of staff at both facilities. Similar gaps exist in the Upper East Northern Regions. ${ }^{23}$ These findings are consistent with other studies in 10 referral district hospitals in Ghana, ${ }^{20}$ India, Tanzania and Ethiopia ${ }^{36}$ and other developing countries. ${ }^{173738}$ Shortage of, and limited access to, licenced staff lends support to the view of some writers that utilising appropriately trained TBAs, CHNs and ENs in mainstream childbirth care in Ghana could reduce some of the current frustrations associated with managing obstetric complications and referral processes ${ }^{25}$ although this is not without its challenges. It was found that poor treatment of pregnant women discouraged skilled maternal health service utilisation with its attendant implications on health outcomes in the rural communities. ${ }^{28}$ Although many of these behaviours could be attributed to the role stress identified in this study, they nevertheless defy professional codes of conduct and the priorities of the country and stakeholders in general. ${ }^{28}$

The Ministry of Health is a policy-oriented body, while Ghana Health Service implements its initiatives. Based on the Ministry's Programme of Work (2014-2017), there were initiatives by Ghana Health Service to increase the country's performance on $\mathrm{MNH}$ indicators in particular, through ANC defaulter tracing, home visiting and free ANC services for all mothers with active National Health Insurance Scheme (NHIS) subscriptions, focussing on preventive care through the sub-district structures. ${ }^{14} 23$

Despite these initiatives, many factors limited the quality of care provided at the facilities, such as general underinvestment in the health system regarding health workforce, medical equipment and medicines, coupled with other multisectoral constraints such as poor road infrastructure, electricity and water. Systemic issues including disrespect, irregular service availability at subdistrict facilities and midwife absenteeism had a significant impact on service delivery.

Efficient lighting systems, water facilities and essential medicines reportedly motivate and increase skilled health services uptake. However, reduced laboratory services and inadequate space and equipment in childbirth rooms in all healthcare settings provided limited confidence to women accessing ANC and contemplating birthing in the health facility. Similar findings were reported elsewhere in the UWR of Ghana and Kenya. ${ }^{1425} 39$ The challenges influenced born-before-arrival syndrome in the UWR. ${ }^{25}$ An evaluation in Ghana, Malawi and Kenya also found informal cost and cultural appropriateness of ANC services as key motivators to patronising skilled maternity care. ${ }^{40}$ In most locations in this study, healthcare facilities were rudimentary, and while the hospital had better equipment and amenities (compared with the HCs and CHPS compounds), irregular power supply had similar negative impacts on service delivery. ${ }^{5}$ The health facilities with intermittent electricity supply were unable to conduct deliveries at night. Most subdistrict health facilities (CHPS compounds) had inadequate access to vaccine fridges and the power grid to store vaccines and having to travel for long distances for necessary vaccines such as tetanus toxoid injection and antimalaria prophylaxis diminished efficacy and efficiency of the healthcare delivery system. ${ }^{41}$ Some facilities had no readily available medicines such as oxytocin to induce labours. Other referrals were prompted by NHIS drug policy that prevents the staff at CHPS compounds from prescribing necessary antibiotics to newly delivered women, suggesting that revision of the NHIS user-fee exemption policy on maternal and neonatal healthcare would be appropriate. ${ }^{14}$ These findings are congruent with other studies in India and a systematic review on this subject. ${ }^{17} 42$ An earlier evaluation in district hospitals in Ghana revealed that they were the highest referral point for many obstetric complications. Meanwhile, many of them did not have the necessary logistics and staff to manage normal childbirth labour and complications. ${ }^{20}$

The project for improvement of maternal and child health in the UWR by the Japan International Cooperation Agency provided elaborate education for district and subdistrict healthcare staff on managing emergency referrals. ${ }^{43}$ A fundamental requirement was to have the midwife accompany the client to the receiving facility. However, considering the staffing inadequacies and the lack of transport services linking the communities, coupled with the behavioural norms on early decisions to seek care, ${ }^{516}$ this approach may further intensify the current shortages of midwives and result in adverse outcomes, due to the distances and the lack of readiness for complications identified in another component of the study. ${ }^{544}$ The geographical isolation of communities from referral centres, and between health facilities, is much like those experienced in other isolated locations, such as Uttar Pradesh, India. ${ }^{37}$ A key difference from the Indian situation may be the fact that the main referral hospital (at Nadowli) serving both districts had no ambulance facility to conduct timely transfer of obstetric emergencies and preterm babies to appropriate health facilities such as Jirapa Hospital or Wa Hospital, which were the nearest regional hospitals.

Although by convention all health facilities in Ghana operate 24 hours a day, there was the tendency to deny clients emergency care at certain times, thereby defying the core mandate of the subdistrict health structures of providing preventive and basic curative care including obstetric first aid. ${ }^{23} 2533$ The common limitations related to hospital referral (mostly Nadowli or Wa) and means of transport create dissonance between the already aggrieved expectant mother in pain and the possibly stressed nurse who provides care to a large population on the one hand, and the healthcare targets/indicators on the other. 
Non-availability and affordability of transport and telecommunication systems during obstetric emergencies influenced referrals to Nadowli and Wa hospitals (the closest to study communities) from subdistrict health facilities. The findings demonstrated that demand for skilled care was on the increase, but the absence of ambulance/vehicular linkage and coverage could delay or cancel obstetric referrals despite regular demand for transfers from lower level facilities. The challenges identified in this study corresponded to those already identified elsewhere in rural Ghana, suggesting the need to streamline referral management systems, which are critical to reducing avoidable mortalities and inequities in access. ${ }^{514} 23$ Studies by Buor and colleagues ${ }^{45} 46$ in Ghana and SSA, and another study in the UWR, demonstrated that distances to health facilities contributed to reduced utilisation and outcomes of obstetric referrals, ${ }^{47}$ thereby providing pregnant women with fewer alternatives during labour and in the event of complications and. ${ }^{25}$ This study may have underestimated the impact of these barriers compared with previous evaluations on this subject, but the adverse effects of home or born-before-arrival syndrome at the health facility are consistent with other research. ${ }^{25} 42$

\section{Implications for future research, policy and maternal health service delivery}

Reports show that Ghanaians have increased utilisation of skilled maternal healthcare, ${ }^{23} 27$ which implies that policy initiatives to address current systemic bottlenecks would provide a way forward towards achieving global goals for the country. This is particularly important because the majority of the chronic health cases leading to life-threatening disabilities and mortalities are found in the hardto-reach communities of the country. ${ }^{35}$ For example, an evaluation in Ghana noted that although the national health insurance fee exemption policy has increased service uptake, inequities and geographical disparities in access continue to exist between the rural poor and nonpoor, thereby causing low use among the poor due to the informal costs of services and medicines. ${ }^{35}$

The many barriers in this study are interdependent, and addressing them will require a holistic approach, including community awareness and proactivity in managing obstetric complications, to help health providers tackle the issues appropriately and on time. Whereas these shortages in the health facilities may not be addressed in the short to medium term due to cost implications, preventative measures could be facilitated at the community level to influence behaviour and cultural change (as identified in other components of the study $)^{51644}$ to help improve MNH outcomes.

Instituting motivational packages (housing, additional allowances and career opportunities) for physicians and midwives may have some potential to encourage staff to accept postings to rural areas, but the lack of equipment and essential medicines for service delivery, continued knowledge and skill development could serve as a limitation. Global technological advancement and professional networking through social media, telecommunication and general internet services via reliable internet networks engender increased ambitions to advance in skills through education and career. However, the gap in these services to the district level was extensive, suggesting that improving the mobile telecommunication network and general internet services at this level could also motivate acceptability of postings to these locations. That aside, facilitating emergency referrals from the subdistrict health facilities to the HCs and the hospital could also improve with improved and reliable telecommunication networks.

\section{Strengths and limitations of this study}

This study has several strengths. It contributes to the scant literature on the barriers to service delivery and access to services that impact MNH care in the UWR of Ghana. The majority of obstetric complications with profound impacts on MNH indicators occur in the rural communities. Therefore, a brief assessment of issues pertaining to the HCs and CHPS zones could trigger policy initiatives and district level oversight responsibilities.

Despite the strengths, the study has limitations. A purposive sampling approach was used to obtain data from the participants. Critics question the credibility of data from such sampling procedures, ${ }^{48}$ but this study was the first of its kind in these districts and considering the findings, supported by general facility observation and cues during the interviews, it is reasonable to say relevant data were generated through the approach to support the research objective. The sample was relatively small compared with the established norm; however, as a mixed method study, data from the other participant groups were used to support and cross-validate those of the healthcare settings; these results are reported elsewhere. ${ }^{5}$

\section{CONCLUSION}

The health facilities at both grassroots and referral hospital levels in the districts were not adequately prepared to provide quality maternal and neonatal healthcare, contributing, at least in part, to the preference of many mothers to eschew ANC and favour a home birth. These factors present a discrepancy between policy and implementation. Some policies and health reforms identified in the study, including task-shifting, the 24-hour policy, drug prescriptions, staff relocation and the legal restrictions on antibiotic prescriptions under NHIS reimbursement mechanisms, had a profound impact on health system performance and adequate and quality MNH care, as well as affecting referral management.

Improving MNH services provided at healthcare facilities by increasing the availability of doctors, midwives, anaesthetists, labour beds, resuscitation equipment, essential medicines, ambulance services and improving access to basic amenities such as electricity and water facilities will assist rural Ghana to achieve the critical SDG 3 (targets one and two) by 2030. The study recommends revisions to the prescription components of the 
NHIS, investigation of the code of conduct of nurses and increased investment in logistics, as well as the management of staff postings.

Acknowledgements The authors are indebted to the management and staff of Ghana Health Service in the study districts especially Mr Richard Basadi (Regional Health Directorate, UWR), Madam Florence Angsomwine (Health Service Director, Nadowli-Kaleo), Dr Frank Teng-Zeng; FT (University for Development Studies, Wa) and Mr Emmanuel Sanwuok (Health Service Director, Daffiama-Bussie-Issa) for their contributions to the study.

Contributors Conceived and designed: all authors. Participant recruitment: JS and JC. Data collection, analysis, interpretation and writing of the first draft of the manuscript: JS. Contribution to study interpretation and manuscript review: all authors. All authors contributed substantially to the writing of the manuscript, reviewed and approved the final write-up for submission.

Funding This research is funded by Ghana Education Trust Fund (GETFUND) Doctorate Studentship to JS.

Disclaimer GETFUND had no role in the study design, data collection and analysis, decision to publish or preparation of the manuscript.

Competing interests None declared.

Patient consent Obtained.

Ethics approval Ethical approvals from Charles Sturt Human Research Ethics Committee (protocol numbers: 2016/013 and H16178 and Regional Health Directorate of Upper West Region.

Provenance and peer review Not commissioned; externally peer reviewed.

Data sharing statement № additional data are available.

Open access This is an open access article distributed in accordance with the Creative Commons Attribution Non Commercial (CC BY-NC 4.0) license, which permits others to distribute, remix, adapt, build upon this work non-commercially, and license their derivative works on different terms, provided the original work is properly cited, appropriate credit is given, any changes made indicated, and the use is non-commercial. See: http://creativecommons.org/licenses/by-nc/4.0/.

\section{REFERENCES}

1. WHO. Maternal mortality. WHO News/Fact sheets, 2018.

2. Coburn C, Restivo M, Shandra JM. The African Development Bank and women's health: a cross-national analysis of structural adjustment and maternal mortality. Soc Sci Res 2015;51:307-21.

3. Paxton A, Maine D, Freedman L, et al. The evidence for emergency obstetric care. Int J Gynaecol Obstet 2005;88:181-93.

4. UNICEF. Trends in maternal mortality: 1990 to 2015. 2015.

5. Sumankuuro J, Crockett $\mathrm{J}$, Wang $\mathrm{S}$. Maternal health care initiatives: Causes of morbidities and mortalities in two rural districts of Upper West Region, Ghana. PLoS One 2017;12:e0183644.

6. Galaa SZ, Haruna U, Dandeebo G. Trends and Causes of Maternal Mortality at the Wa Regional Hospital, Ghana: 2005-2010. Ghana Journal of Development Studies 2016;13:80-96.

7. UNFPA. Ghana; accelerating progress towards MDG5. United Nations Population Fund G, ed. Facts Sheet. UNFPA Home Page, 2014.

8. Maine D, Wardlaw TM, Ward VM, et al. Guidelines for monitoring the availability and use of obstetric services. 1997.

9. Hoyler M, Finlayson SR, McClain CD, et al. Shortage of doctors, shortage of data: a review of the global surgery, obstetrics, and anesthesia workforce literature. World J Surg 2014;38:269-80.

10. Fapohunda BM, Orobaton NG. When women deliver with no one present in Nigeria: who, what, where and so what? PLoS One 2013;8:e69569.

11. Goodburn EA, Chowdhury M, Gazi R, et al. Training traditional birth attendants in clean delivery does not prevent postpartum infection. Health Policy Plan 2000;15:394-9.

12. Finlayson $\mathrm{K}$, Downe $\mathrm{S}$. Why do women not use antenatal services in low- and middle-income countries? A meta-synthesis of qualitative studies. PLoS Med 2013;10:e1001373.

13. Sumankuuro J, Crockett J, Wang S. Antenatal care on the Agenda of the Post-Millennium Development Goals in northern Ghana. International Journal of Innovation and Applied Studies 2016;18:341-52.
14. Ganle JK, Parker M, Fitzpatrick R, et al. Inequities in accessibility to and utilisation of maternal health services in Ghana after user-fee exemption: a descriptive study. Int J Equity Health 2014;13:89.

15. Sumankuuro J, Crockett J, Wang S. Factors influencing knowledge and practice of birth preparedness and complication readiness in sub-saharan Africa: a narrative review of cross-sectional studies. Int J Community Med Public Health 2016;3:3297-307.

16. Sumankuuro J, Crockett J, Wang S. Sociocultural barriers to maternity services delivery: a qualitative meta-synthesis of the literature. Public Health 2018;157:77-85.

17. Knight HE, Self A, Kennedy SH. Why are women dying when they reach hospital on time? A systematic review of the 'third delay'. PLoS One 2013:8:e63846.

18. Bossyns P, Abache R, Abdoulaye MS, et al. Monitoring the referral system through benchmarking in rural Niger: an evaluation of the functional relation between health centres and the district hospital. BMC Health Serv Res 2006;6:1-7.

19. Sakeah E, McCloskey L, Bernstein J, et al. Can community health officer-midwives effectively integrate skilled birth attendance in the community-based health planning and services program in rural Ghana? Reprod Health 2014;11:90.

20. Abdullah F, Choo S, Hesse AA, et al. Assessment of surgical and obstetrical care at 10 district hospitals in Ghana using on-site interviews. J Surg Res 2011;171:461-6.

21. World Bank Group and the United Nations Population Division. Trends in maternal mortality: 1990-2015: estimates from WHO, UNICEF, UNFPA: WHO, UNICEF, UNFPA, 2015.

22. WB. World Development Indicators, the World Bank. World Development Indicators, The World Bank 2016.

23. MoH. Health Sector Medium Development Plan (2014-2017. AccraGhana: Ministry of Health, 2014

24. WHO. Health workforce requirements for universal health coverage and the sustainable development goals. 2016

25. Rishworth A, Dixon J, Luginaah I, et al. "I was on the way to the hospital but delivered in the bush": Maternal health in Ghana's Upper West Region in the context of a traditional birth attendants' ban. Soc Sci Med 2016;148:8-17.

26. Dzakpasu S, Soremekun S, Manu A, et al. Impact of free delivery care on health facility delivery and insurance coverage in Ghana's Brong Ahafo Region. PLoS One 2012;7:e49430.

27. Singhateh SK, Dzisi SA, Adadevoh S, et al. Final evaluation report: UNFPA 5th country program (2006-2010). Ghana: UNFPA, Ghana, 2010.

28. Moyer CA, Adongo PB, Aborigo RA, et al. 'They treat you like you are not a human being': maltreatment during labour and delivery in rural northern Ghana. Midwifery 2014;30:262-8.

29. GSS. 2010 Population and Housing Census. Daffiama-Bussie-Issa District Analytical Report. Ghan, Accra: Ghana Statistical Service, 2014.

30. GSS. Population and Housing Census. Nadowli - Kaleo District Analytical Report. Ghana, Accra: GoG, 2014.

31. Bloomberg School of Public Health CfCP, Family Care International, ed. Maternal and Neonatal Health. Monitoring birth preparedness and complication readiness. Tools and indicators for maternal and newborn health. USA: Hopkins, 2004

32. WHO. WHO standards of care to improve maternal and newborn quality of care in facilities. A Network for Improving Quality of Care for Maternal NCH. Geneva: WHO, 2017.

33. MoH. Referal policy and guidelines: Government of Ghana, 2014:26.

34. WHO. Process of translation and adaptation of instruments. Geneva: WHO, 2017.

35. Saleh K. The Health Sector in Ghana: a comprehensive assessment: World Bank Publications. 2012.

36. Bayu H, Fisseha G, Mulat A, et al. Missed opportunities for institutional delivery and associated factors among urban resident pregnant women in South Tigray Zone, Ethiopia: a community-based follow-up study. Glob Health Action 2015;8:28082.

37. Raj SS, Manthri S, Sahoo PK. Emergency referral transport for maternal complication: lessons from the community based maternal death audits in Unnao district, Uttar Pradesh, India. Int J Health Policy Manag 2015;4:99-106.

38. Nyamtema A, Urassa D, Massawe S, et al. Staffing needs for quality perinatal care in Tanzania. African journal of reproductive health $2008 ; 12$.

39. Ochako R, Fotso JC, Ikamari L, et al. Utilization of maternal health services among young women in Kenya: insights from the Kenya Demographic and Health Survey, 2003. BMC Pregnancy Childbirth 2011;11:1.

40. Pell C, Meñaca A, Were F, et al. Factors affecting antenatal care attendance: results from qualitative studies in Ghana, Kenya and Malawi. PLoS One 2013;8:e53747. 
41. Thaddeus S, Maine D. Too far to walk: maternal mortality in context. Soc Sci Med 1994;38:1091-110.

42. Singh A. Supply-side barriers to maternal health care utilization at health sub-centers in India. PeerJ 2016;4:e2675.

43. Ampiah K. The Discourse of Japanese Development Assistance and the Scaling-up of Community-based Health Planning and Services (CHPS) in Ghana. JICA Research Institute 2017:149.

44. Sumankuuro J, Crockett J, Wang S. The use of antenatal care in two rural districts of Upper West Region, Ghana. PLoS One 2017;12:e0185537.
45. Buor D. Determinants of utilisation of health services by women in rural and urban areas in Ghana. GeoJournal 2004;61:89-102.

46. Buor D, Bream K. An analysis of the determinants of maternal mortality in sub-Saharan Africa. J Womens Health 2004;13:926-38.

47. Atuoye KN, Dixon J, Rishworth A, et al. Can she make it? Transportation barriers to accessing maternal and child health care services in rural Ghana. BMC Health Serv Res 2015;15:1-10.

48. Polit DF, Beck CT. The content validity index: Are you sure you know what's being reported? critique and recommendations. Res Nurs Health 2006;29:489-97. 